ray absorptiometry (Lunar iDXA 16[SP2]) with pediatric database in lumbar spine (L1-L4) and in total body less head (TBLH); iii) bone age with Greulich-Pyle method; iiii) Tanner's puberty stage and anthropometry. In the cases with significant growth delay or acceleration the height- or biologic age standardization for bone mineral density (BMD) applied

Results The BMD Z score -1SD to - 2SD was in 15 (26.3\%) children and $Z$ score $<-2$ SD in 5 (8.8\%). All children with BMD L1-L4 Z score <-2SD had growth delay so after applying of above mentioned correction methods where were no patients with severe bone mineral density (Zscore $<-2$ SD) deficiency. Only 3 children had decreased (near -2SD) BMD in total body less head program. No patients with pathological low-energy fractures were observed.

Conclusion We have not found osteoporotic CF patients. Further investigations required for cystic fibrosis patients with borderline decreased bone mineral density (near or less than $2 \mathrm{SD})$.

\section{P34 THE LONG-TERM RESULTS OF SINGLE-EVENT MULTILEVEL SURGERY IN TREATMENT OF CHILDREN WITH SPASTIC DIPLEGIA}

${ }^{1}$ Mikhail Herasimenka, ${ }^{2}$ Leanid Hlazkin*, ${ }^{2}$ Mikhail Mikhovich, ${ }^{3}$ Raman Klimau, ${ }^{1}$ Aleh Sakalouski. 'Republican Scientific and Practical Centre for Traumatology and Orthopaedics, Minsk, Belarus; ${ }^{2}$ Mogilev Regional Children's Hospital, Mogilev, Belarus; ${ }^{3}$ Brest Regional Children's Hospital, Brest, Belarus

\subsection{6/archdischild-2019-epa.389}

Introduction Cerebral palsy is a group of permanent disorders of the development of movement and posture, causing activity limitation, that are attributed to non-progressive disturbances that occurred in the developing fetal or infant brain. Single-Event Multilevel Surgery - SEMLS has been used by most surgeons for correction limb deformities in the past decades.

The aim Of our study was to evaluate the long-term results of SEMLS, performed in the Mogilev Regional Children's hospital and in the Republican Scientific and Practical Centre for Traumatology and Orthopaedics.

Materials and methods The long-term results of SEMLS in 19 children with spastic diplegia, operated in 2009-2016 were studied. All the patients had spastic deformities of the hips, knees and ankles on the both sides before surgery. All the patients were GMFCS IV. The mean age at time of surgery was 6,7. 138 procedures were performed. All the procedures were made simultaneously on the both sides by two teams of surgeons. Observational Gait Scale (OGS) and Edinburgh Visual Gait Score (EVGS) were used to determine the effectiveness of treatment.

Results The minimal follow-up was 3 years. The mean improvement by OGS was 8,5 , the minimal improvement -3 , maximal - 12. The mean improvement by EVGS was 10,1 , the minimal improvement -6 , maximal -16 . All the parents noticed the improvements in child's mobility after surgery. One patient has severe valgus foot deformity and calcaneal gait after anterior Achilles tendon transfer as part of SEMLS in 2015. Six patients underwent additional surgery for correction of the secondary bone deformities later.

Conclusions Brain disorders in cerebral palsy are permanent and as S.Terver said - 'The child with cerebral palsy becomes the adult with cerebral palsy'. For the child with cerebral palsy the main goals of surgical treatment - improving the child's motor activity and elimination of severe limb deformities.

SEMLS changes the whole pathological stereotype of musculoskeletal balance of extremities. It can improve the child's motor activity, eliminate the severe contractures of joints, provide adequate care for him in a relatively short period of time and save these improvements in the longterm follow-up. Care must be taken in choosing the proper method of surgical correction, especially in treatment of equinus.

\section{P35 IMPROVED SURVIVAL IN RARE RECESSIVE OSTEOGENESIS IMPERFECTA THROUGH MULTIDISCIPLINARY TEAM SUPPORT AND EARLY BISPHOSPHONATE USE}

${ }^{1}$ Gillian O'Donnell*, 'Laura C McCarron, 'Eleanor Burke, ${ }^{1,2}$ Ciara M McDonnell. 'Department of Paediatric Endocrinology, Children's University Hospital, Temple St, Dublin, Ireland; '2Discipline of Paediatrics, University of Dublin, Trinity College, Dublin, Ireland

\subsection{6/archdischild-2019-epa.390}

Osteogenesis imperfecta (OI) or Brittle bone disease is a rare genetic connective tissue disorder with the majority of mutations found in collagen type 1 genes (COL1A1/ COL1A2) or their related SIBLING proteins. The condition is characterized by increased bone fragility, resulting from abnormal collagen formation. Recessive forms of OI are associated with increased severity and lethality due to mutations in LEPRE1, encoding prolyl 3-hydroxylase-1 (P3H1) or in CRTAP, encoding cartilage associated protein. The LEPRE1 gene mutation has been expressed in the Irish Traveller population. We report two children affected with this mutation who have demonstrated a positive response to early bisphosphonate use.

Case 1 A male infant was born in 2013 by elective LSCS at 38 weeks gestation to consanguineous Caucasian parents from the Irish traveller community. Antenatal scans in the third trimester had confirmed multiple in utero fractures. He was commenced on Pamidronate (Bisphosphonate) infusion at four weeks of age. He now sits and transfers independently and is attending school.He has sustained further fractures with trauma.

Case 2 A male infant was born in 2018 by elective LSCS at 39 weeks gestation to consanguineous Caucasian parents from a separate family tribe within the Irish traveller community. Antenatal scans at 22 weeks confirmed limited femur growth and the possibility of skeletal dysplasia were raised at 23 weeks when significant fractures were noted. There was a strong family history of osteogenesis imperfecta with the death of four of his mother's siblings in childhood with a clinical diagnosis of brittle bone disease. She was believed to be unaffected having never sustained a fracture.He was commenced on an initial dose of zoledronic acid on Day 7 of life with a subsequent reduction in analgesia requirement and increase in peripheral limb activity. He was discharged home at 4 weeks of age.

Discussion Molecular genetics confirmed a diagnosis of type VIII OI caused by a pathogenic mutation in the LEPRE1 (P3H1) gene in both cases. Skeletal survey at birth showed thin ribs, multiple wormian bones and healing fractures of the clavicles, ribs, humeri and femori. Both exhibited a 